\title{
Editorial
}

\section{Forming and Heat Treatment of Modern Metallic Materials}

\author{
Ján Moravec $1, * \mathbb{D}$ and Karel Gryc ${ }^{2}$
}

1 Department of Technological Engineering, Faculty of Mechanical Engineering, Univesity of Zilina, Univerzitná 8215/1, 01026 Žilina, Slovakia

2 Environmental Research Department, Institute of Technology and Business in České Budějovice, Okružní 517/10, 37001 České Budějovice, Czech Republic; 23145@mail.vstecb.cz

* Correspondence: Jan.Moravec@fstroj.uniza.sk; Tel.: +421-910-280-573

Citation: Moravec, J.; Gryc, K. Forming and Heat Treatment of Modern Metallic Materials. Metals 2021, 11, 1106. https://doi.org/ $10.3390 /$ met11071106

Received: 11 May 2021

Accepted: 8 July 2021

Published: 12 July 2021

Publisher's Note: MDPI stays neutral with regard to jurisdictional claims in published maps and institutional affiliations.

\section{Introduction and Scope}

Forming and heat treatment of metals are crucial technologies for final metallic material processing at the end of production line, before they are incorporated into the final products or crucial components of more and more demanding systems required for the sustainability and development and of our civilization.

Thus, the content of this Special Issue "Forming and Heat Treatment of Modern Metallic Materials" focuses not only on standard technologies but also on new procedures and approaches verified in laboratory and operational conditions. Contributions to this issue will represent papers from the academic sphere as well as the production sphere. Topics covering the wide spectrum of various production methods and solutions based on non-conventional approaches mostly derived from physical knowledge are welcome. Papers should provide a base for further use and extraction of introduced knowledge by scientific and technical society.

\section{Contribution to the Special Issue}

The contributions are divided into three basic groups. The division and classification of contributions is made on the basis of the main problems published in the text. The first can be characterized as materials for forming and their study, together with hot forming, where the papers are presented [1-4]. The second group consists of contributions devoted to shaping and unconventional shaping [5-7]. The third group includes those articles that deal with the field of heat treatment [8-13]. Perhaps the contributions could be divided in other ways, but we consider this appropriate.

In the presented work [1], based on a dynamic material model, processing maps of low-alloy steel 10CrMo9-10 were compiled, using two sets of flow curve data. For the extruded state of the 6082 alloy, the physically based model was developed to reliably predict the flow stress influenced by dynamic softening, temperature, strain rate, and true strain up to 0.6 [2]. The relationship between microstructure parameters and mechanical properties was studied by authors [3]. The strength followed a Hall-Petch relationship with the austenite grain size, but the austenite grain size has nothing to do with the impact toughness. One paper [4] considered the factors of the austenitizing temperature, the austenitizing time and the cooling rate, a coupled model on the thermal homogenization and established the phase transition from austenite to martensite in quenching process for production of ultra-high strength hot-stamping steel.

The second group consists of manuscripts devoted to ducting and unconventional forming. A research work [5] is primarily focused on investigating the effects of changing rotational speed on the forming temperature and microstructure during incremental sheet metal forming (ISF) of AA-2219-O and AA-2219-T6 sheets. The results reveal that the density of second phase particles reduces with increasing speed reasoning to corresponding temperature rise. Bipolar plates are a major part of fuel cells, which are a clean and 
recyclable energy source. A study [6] was carried out with two dies for a bipolar plateforming investigation with the magnetic pulse method: a bipolar plate die and a 10channel die. An article [7] is focused on an analysis of factors negatively affecting the production process of tubes made from austenitic stainless steel with a very small diameter of $\phi 0.34 \mathrm{~mm}$. The analysis was concentrated on factors that affect the drawing process stability of the seam tubes where the final dimensions are desired.

The third group includes articles that are devoted to the field of heat treatment. Irradiation experiments and thermal field simulation revealed that the energy density of the ion beam plays a predominant role in the irradiation effect; with low energy density, the flow of molten surface is too weak to smooth the fluctuations on the surface [8]. In another study [9], a novel approach for inducing magnetic anisotropy by applying radial stresses on tape-wound cores ribbon during crystallization heat treatment was utilized. The influence of electropulses in situ on the drawing process of copper wires was investigated, with the aim of avoiding time consuming annealing thermal treatments. It was found that with the application of electropulses, tensile and drawing forces were reduced, and the plasticity of the wire was improved [10]. A non-uniform temperature across the width of martensitic stainless-steel strips is considered to be one of the main reasons why the strip exhibits un-flatness defects during the hardening process. Therefore, the effect of the gas inlet position on the temperature distribution of the steel strip in this process was investigated numerically [11]. Cast Mg-9Li alloy was a successfully solid solution (SS) treated via heating at $575^{\circ} \mathrm{C}$ for $4.5 \mathrm{~h}$ and then rapidly quenching it with ice-water mixture. The mechanical property and corrosion resistance of the SS alloy were simultaneously improved. Rapid bcc/hcp phase transition of the alloy occurred during the quenching process, creating the newly precipitated needle-like fine $\alpha$-Mg phase, uniformly distributed in the $\beta$-Li phase matrix [12]. The dimension quality of the strip within the hardening process is an essential parameter, which needs to be paid great attention to. The flatness of the final product is influenced by the temperature distribution of the strip, specifically across the width direction. Therefore, based on physical theories, a numerical model was established [13].

\subsection{Studies of Materials for Forming and Hot Forming}

Authors Opěla et al. [1] stated that the process map processing is a support tool for optimizing thermoforming processes. Processing maps of low-alloy steel 10CrMo9-10 were compiled, using two sets of data on the flow curve on the basis of a dynamic material model. This experimental data set was subsequently approximated, using an artificial neural network approach. Based on this approximation, a second data set was determined by calculation. The benefit is that the additional data set has significantly contributed to improving the information capability of the compiled process maps in terms of detecting potentially inappropriate molding conditions. The contribution is a suitable support for the area of volume hot forming of metals.

The determination of the stress-deformation curves of aluminum alloy EN AW 6082 with $1.2 \mathrm{Si}-0.51 \mathrm{Mg}-0.75 \mathrm{Mn}$ (wt.\%) by uniaxial compression tests at temperatures of $450-550{ }^{\circ} \mathrm{C}$ with a deformation rate of $0.5-10 \mathrm{~s}^{-1}$ was described by Schindler et al. [2]. The initial state of the structure corresponded to three types of processing: the cast structure either not homogenized or homogenized at $500{ }^{\circ} \mathrm{C}$, and the structure after homogenization and hot extrusion. The $Q$ values of the activation energy during hot deformation ranged between 99 and $122 \mathrm{~kJ} \cdot \mathrm{mol}^{-1}$ for both homogenized materials and from 200 to $216 \mathrm{~kJ} \cdot \mathrm{mol}^{-1}$ for the cast state. $Q$ values were determined from the measured data set; a physically based model was developed for the extruded state of alloy 6082 to reliably predict the flow stresses affected by dynamic softening, temperature, strain rate, and true strain up to 0.6.

The authors Zhang et al. [3] studied the relationship between microstructure parameters and mechanical properties. The steel was heat-treated at different austenitization temperatures to obtain a changing microstructure. The results showed that the size of the austenitic grains increases with the austenitization temperature, while the size of the 
pearlite colonies is relatively constant. The control unit for determining the impact strength of pearlitic steel is the size of the pearlite colony, using a comparative method. Eutectoid steel with a carbon content of $0.81 \%$, when undergoing isothermal conversion, has a very small number of precipitates at the grain boundary. Pearlite colonies randomly nucleate at grain boundaries and grow into the interior of the grains. At the same time, new pearlite colonies nucleate alongside an existing pearlite colony. Intragranular colonies of pearlite are also randomly nucleated.

Liu et al.'s [4] paper focuses on the hot-pressing process, which is widely used in the production of high-strength automotive steel, including the process of pressing and hardening hot-formed steel. In the hot-pressing process, the steel is heated above the critical austenitization temperature, then rapidly pressed into a mold, and at the same time a hardening phase transition occurs. A combined model of thermal homogenization and phase transition from austenite to martensite in the hardening process for the production of ultra-high-strength hot-pressed steel was studied. The microstructure and properties of high-strength hot-pressed steel after hardening at different austenitization temperatures were also studied experimentally. The results show that under low cooling rate conditions, the final hardening microstructure of the ultra-high strength hot-stamping steel includes martensite, residual austenite, bainite and ferrite. The results show how the shaping intersects with the thermal processes of heating, and how it is sometimes difficult to establish the exact boundary between them.

\subsection{Shaping and Unconventional Shaping Issues}

Riaz et al. [5] focused on investigating the effects of changes in rotational speed on the forming temperature and microstructure during the forming of sheets AA-2219-O and AA-2219-T6 during sequential forming (ISF). The plates were formed into pyramid shapes with a tensile angle of $45^{\circ}$ with a hemispherical end-forming tool with a diameter of $12 \mathrm{~mm}$. During sheet forming, temperature changes due to friction in the contact zone of the sheet with the tool were recorded, using a non-contact laser infrared temperature sensor. The effects of rotational speed and the associated temperature increase were investigated on a microstructure, using a scanning electron microscope (SEM). The results show that the particle density of the second phase decreases with increasing rate of thought of a corresponding increase in temperature. However, the particle size at both AA2219 temperatures changed slightly.

Authors Wang et al. [6] performed a study, using two matrices to investigate the formation of a bipolar plate by the magnetic pulse method: a bipolar plate matrix and a 10-channel matrix. The maximum average depth in percent was $86 \%$ for $\mathrm{Cu} 110$ sheet, while it was $54 \%$ for second grade Ti sheet. Increasing the percentage of depth requires much higher energy from the condenser bank. In the case of a 10-channel matrix, the influence of the matrix parameters on the sheet forming was examined, using Cu110 sheet and SS201 sheet. The immersion angle had a significant effect on the replication of the matrix surface. Full replication was achieved for channels with the correct parameters with both Cu110 and SS201.

The analysis presented by Schreck et al. [7] focused on the factors that affect the stability of the seam pipe drawing process, where the limiting factors are the required final dimensions: diameter $\sim 0.34 \mathrm{~mm}$ and wall thickness $0.057 \mathrm{~mm}$. Seam tubes made of 1.4306 and 1.4301 steel with a longitudinal welding line welded with tungsten inert gas (TIG) were used as semi-finished products for drawing operations.

\subsection{Heat Treatment of Metallic Materials}

Min et al. [8] applied intense pulsed ion beam irradiation to IN718 superalloy. It has been shown that an intense pulsed ion beam composed of protons and carbon ions can induce surface melting and the surface roughness varies significantly due to the formation of micro-faults and the flow of the molten surface. Irradiation experiments and thermal field simulation have revealed that the energy density of the ion beam plays a dominant 
role in the irradiation effect; at low energy densities, the flux of the molten surface is too weak to smooth out surface fluctuations. With a high energy density, the surface can be effectively melted and smoothed.

In their study, Xue et al. [9] used a new approach to the induction of magnetic anisotropy, which involved the action of radial stresses on nuclei during heat treatment by crystallization. The results showed that while stress annealing does not change the structural characteristics of the annealed samples, the induced magnetic anisotropies can increase to values 3-5 times greater than the annealed samples in the absence of external stress. The results suggest that the magnetic properties of nanocrystalline soft magnetic alloys can be effectively tuned by radial stresses.

The influence of electropulses on the process of drawing copper wires was investigated by Rojas et al. [10], in order to avoid time-consuming heat treatment-annealing. It has been found that the use of electropulses reduces tensile strength and tensile stress and improves the plasticity of the wire. No significant differences in material resistance were found during electropulse processing. The authors presented the first evidence of the advantages of this hybrid technique for drawing with pure copper wire and finally replacing the conventional annealing process with a more time-efficient electropulse drawing process.

Pirouznia et al. [11] addressed the issue of uneven temperature over the entire width of martensitic stainless steel strips, which is considered to be one of the main reasons why the strip shows unevenness during the curing process. An infrared thermal imaging camera was used to compare model predictions and actual process data. The results showed that the temperature difference in the bandwidth changed by $9 \%$ and $14 \%$ compared to the calculated temperature and the measured values. The temperature test was performed at a position about $63 \mathrm{~mm}$ from the bath interface. Furthermore, a more symmetrical temperature distribution over the entire width of the belt was observed. The results show that the effect of belt speed on belt temperature is very small.

The Mg-9Li alloy was worked up to solid solution (SS) for $4.5 \mathrm{~h}$ by heating to $575{ }^{\circ} \mathrm{C}$ and rapidly decomposed with a mixture of ice and water by Wang et al. [12]. At the same time, the mechanical properties and corrosion resistance of the SS alloy were improved. During the hardening process, a rapid phase transition of the alloy occurred, creating a newly precipitated fine needle-like phase similar to the needle, evenly distributed in the $\beta$-Li phase matrix. Dramatic grain refinement and uniform $\alpha-\mathrm{Mg}$ phase distribution, as well as significantly increased $\alpha$-/ $\beta$-phase interfaces, are factors leading to improved mechanical properties of the SS alloy. The findings in this binary Mg-Li alloy can also serve as a yardstick for other more practical and complicated Mg-Li alloys.

Finally, Pirouznia et al. [13] dealt with the issue and quality of strip dimensions in the hardening process, which is an essential parameter and must be given great attention. Based on physical theories, they built a numerical model. The belt temperature in the section before the martensitic transformation was determined in a predicted model, using a steady state approach. The results showed that the temperature of the strip dropped to $250{ }^{\circ} \mathrm{C}$ in the area between the furnace and the hardening bath. This, in turn, resulted in a significant temperature difference in belt width. Overall, this study provided a better overview of the cooling step in the hardening process.

\section{Conclusions}

Presented research articles represent an interesting selection of contemporary knowledge concentrated in this Special Issue "Forming and Heat Treatment of Modern Metallic Materials". The guest editors suppose that these papers should be inspiring for scholars, researchers and technologists. We believe that the presented contributions should help them during new research studies, debates, and discussions related to different ways of forming materials characterization, shaping and forming of metals and heat treatment too. 


\begin{abstract}
Acknowledgments: The guest editors would like to thank all who have contributed directly and indirectly for the successful development of this Special Issue. The guest editors thank all the scholars and authors who submitted their manuscripts and were willing to publish their research activities in this Special Issue. Special mention and sincere thanks to the reviewers, who agreed to review the articles and provide feedback to improve the quality of the manuscripts. Credits should be also given to the editors and to Managing Editor Natalie Sun, and also all the staff of the Metals Editorial Office for their contribution and support in the publication process of this issue.
\end{abstract}

Conflicts of Interest: The authors declare no conflict of interest.

\title{
References
}

1. Opěla, P.; Kawulok, P.; Kawulok, R.; Kotásek, O.; Buček, P.; Ondrejkovič, K. Extension of Experimentally Assembled Processing Maps of 10CrMo9-10 Steel via a Predicted Dataset and the Influence on Overall Informative Possibilities. Metals 2019, 9, 1218. [CrossRef]

2. Schindler, I.; Kawulok, P.; Očenášek, V.; Opěla, P.; Kawulok, R.; Rusz, S. Flow Stress and Hot Deformation Activation Energy of 6082 Aluminium Alloy Influenced by Initial Structural State. Metals 2019, 9, 1248. [CrossRef]

3. Zhang, F.; Zhao, Y.; Tan, Y.; Ji, X.; Xiang, S. Study on the Nucleation and Growth of Pearlite Colony and Impact Toughness of Eutectoid Steel. Metals 2019, 9, 1133. [CrossRef]

4. Liu, S.; Long, M.; Ai, S.; Zhao, Y.; Chen, D.; Feng, Y.; Duan, H.; Ma, M. Evolution of Phase Transition and Mechanical Properties of Ultra-High Strength Hot-Stamped Steel During Quenching Process. Metals 2020, 10, 138. [CrossRef]

5. Riaz, A.A.; Ullah, N.; Hussain, G.; Alkahtani, M.; Khan, M.N.; Khan, S. Experimental Investigations on the Effects of Rotational Speed on Temperature and Microstructure Variations in Incremental Forming of T6-Tempered and Annealed AA2219 Aerospace Alloy. Metals 2020, 10, 809. [CrossRef]

6. Wang, H.; Wang, Y. Investigation of Bipolar Plate Forming with Various Die Configurations by Magnetic Pulse Method. Metals 2019, 9, 453. [CrossRef]

7. Schrek, A.; Brusilová, A.; Švec, P.; Gábrišová, Z.; Moravec, J. Analysis of the Drawing Process of Small-Sized Seam Tubes. Metals 2020, 10, 709. [CrossRef]

8. Min, M.; Ding, S.; Yu, X.; Zhang, S.; Zhong, H.; Remnev, G.E.; Le, X.; Zhou, Y. Investigation of the Effects of an Intense Pulsed Ion Beam on the Surface Melting of IN718 Superalloy Prepared with Selective Laser Melting. Metals 2020, 10, 1178. [CrossRef]

9. Xue, Z.; Li, X.; Sohrabi, S.; Ren, Y.; Wang, W. Magnetic Properties in Finemet-Type Soft Magnetic Toroidal Cores Annealed under Radial Stresses. Metals 2020, 10, 122. [CrossRef]

10. González Rojas, H.A.; Sánchez Egea, A.J.; Hameed, S.; Bolmaro, R. An Ultra-Fast Annealing Treatment by Electropulsing during Pure Copper Wire Drawing. Metals 2019, 9, 1253. [CrossRef]

11. Pirouznia, P.; Andersson, N.Å.I.; Tilliander, A.; Jönsson, P.G. The Impact of the Gas Inlet Position, Flow Rate, and Strip Velocity on the Temperature Distribution of a Stainless-Steel Strips during the Hardening Process. Metals 2019, 9, 928. [CrossRef]

12. Wang, G.; Song, D.; Li, C.; Klu, E.E.; Qiao, Y.; Sun, J.; Jiang, J.; Ma, A. Developing Improved Mechanical Property and Corrosion Resistance of Mg-9Li Alloy via Solid-Solution Treatment. Metals 2019, 9, 920. [CrossRef]

13. Pirouznia, P.; Andersson, N.Å.I.; Tilliander, A.; Jönsson, P.G. An investigation of the Temperature Distribution of a Thin Steel Strip during the Quenching Step of a Hardening Process. Metals 2019, 9, 675. [CrossRef] 